
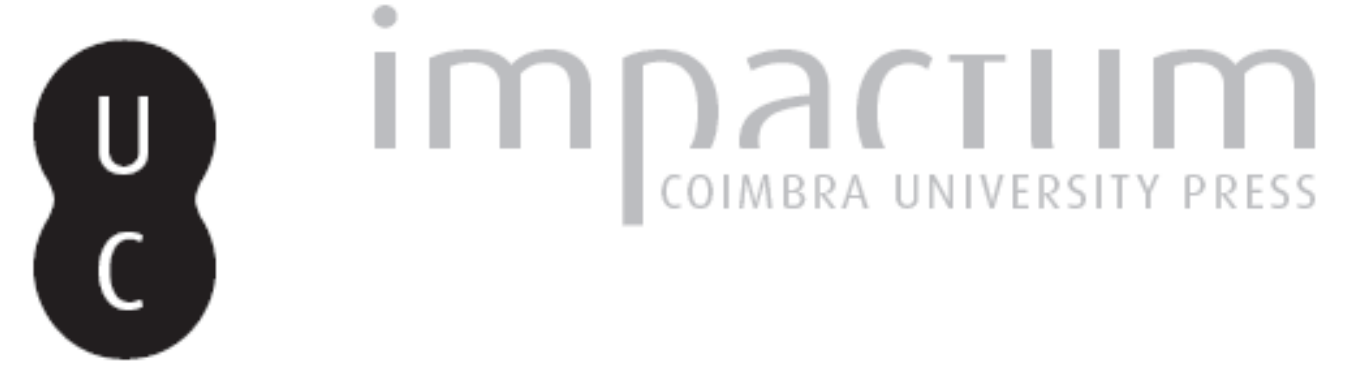

\title{
Presa dos Mouros: uma barragem romana inédita do Algarve (Lagoa)
}

Autor(es): $\quad$ Cardoso, João Luís; Gomes, Mário Varela

Publicado por: Imprensa da Universidade de Coimbra

URL persistente:

URI:http://hdl.handle.net/10316.2/45480

DOI:

DOI:https://dx.doi.org/10.14195/1647-8657_32_33_6

Accessed : $\quad$ 26-Apr-2023 05:14:48

A navegação consulta e descarregamento dos títulos inseridos nas Bibliotecas Digitais UC Digitalis, UC Pombalina e UC Impactum, pressupõem a aceitação plena e sem reservas dos Termos e Condições de Uso destas Bibliotecas Digitais, disponíveis em https://digitalis.uc.pt/pt-pt/termos.

Conforme exposto nos referidos Termos e Condições de Uso, o descarregamento de títulos de acesso restrito requer uma licença válida de autorização devendo o utilizador aceder ao(s) documento(s) a partir de um endereço de IP da instituição detentora da supramencionada licença.

Ao utilizador é apenas permitido o descarregamento para uso pessoal, pelo que o emprego do(s) título(s) descarregado(s) para outro fim, designadamente comercial, carece de autorização do respetivo autor ou editor da obra.

Na medida em que todas as obras da UC Digitalis se encontram protegidas pelo Código do Direito de Autor e Direitos Conexos e demais legislação aplicável, toda a cópia, parcial ou total, deste documento, nos casos em que é legalmente admitida, deverá conter ou fazer-se acompanhar por este aviso. 


\section{UNIVERSIDADE DE COIMBRA \\ FACULDADE DE LETRAS}

\section{CONIMBRIGA}

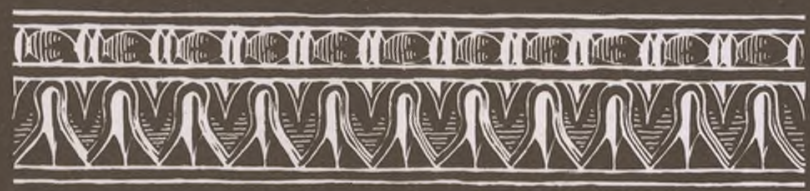

VOLUMES XXXII-XXXIII-1993/94 


\section{JoÃo Luís CARDoso}

Coordenador do Centro de Estudos Arqueológicos do Concelho de Oeiras

- Câmara Municipal de Oeiras

\section{MÁrio VARELA GOMES}

Director dos Museus de Arqueologia de Silves e Montemor-o-Novo.

Da Academia Portuguesa da História

\section{PRESA DOS MOUROS -}

UMA BARRAGEM ROMANA INÉDITA DO ALGARVE (LAGOA)

«Conimbriga» XXXII-XXXIII (1993-1994), p. 137-144

RESUMO: Estuda-se uma barragem romana situada junto da confluência da ribeira do Lageal ou do Vale da Lapa com o Oceano (concelho de Lagoa). Trata-se de uma estrutura constituída por muro rectilíneo, de opus incertum, de blocos irregulares de calcários do Miocènico marinho, disponíveis no local, cimentados por argamassa muito dura de cal e areia.

Apresentam-se paralelos para este tipo de estrutura, referindo-se, no Algarve, as barragens de Fonte Coberta (Lagos) e de Espiche (Lagos), a par de outras, de diferente tipologia.

Discute-se, também, a finalidade desta obra, relacionando-a com a indústria de pescado, atendendo à adjacência imediata de praia onde poderiam ter existido estruturas fabris destinadas àquele fim.

RÉSUMÉ: Dans cet article les auteurs étudient un barrage romain - Presa dos Mouros - localisé près de la confluence de la ribeira do Lageal avec l'Océan (municipalité de Lagoa).

Il s'agit d'une structure constituée par un mur rectiligne, en opus incertum., avec des grands blocs en calcaire du Miocène marin, disponibles localement.

Des comparaisons avec d'autres barrages romans de 1'Algarve ont été effectuées et la finalité est discuté.

La proximité de l'Océan et l'absence de champs agricoles à l'aval, justifient, avec la plus haute probalité, leur rapport avec une usine de salaison, éventuellement située sur la côte, à l'embouchure de la rivière, comme d'autres connues au Portugal. 
(Página deixada propositadamente em branco) 


\section{PRESA DOS MOUROS - UMA BARRAGEM ROMANA INÉDITA DO ALGARVE (LAGOA)}

\section{A descoberta}

O topónimo Presa dos Mouros, registado tanto na edição de 1952 da Carta Militar de Portugal, do Serviço Cartográfico do Exército, folha n. ${ }^{\circ}$ 603, Portimão, à escala 1:25.000, como na edição de 1978, reimpressa em 1987, sugeria a existência de uma obra hidráulica antiga, no Concelho de Lagoa, pelo que um de nós (M.V.G.) o indicou à equipa que o primeiro autor da presente notícia integrava, tendo em vista a elaboração do levantamento e estudo dos aproveitamentos hidráulicos romanos a sul do Tejo (Quíntela, Cardoso e Mascarenhas, 1986). Recordemos que uma barragem romana, no Vale do Olival, no limite daquele mesmo concelho com o de Silves, e não longe de Armação de Péra, é localmente conhecida como Ponte dos Mouros, tendo sido primeiramente referida por Francisco Xavier d'Ataíde Oliveira, na obra " $A s$ Mouras Encantadas e os Encantamentos no Algarve" (1898, 237, 238) e, depois, por outros autores (Gomes e Gomes, 1988, 68).

Tal barragem foi estudada em trabalhos de conjunto sobre barragens romanas do Algarve (Quiniela, Cardoso e Mascarenhas, 1988, 22, 23; 1989, 83; Cardoso, 1990, 91, 92). Refira-se, a propósito, que três outras barragens romanas, a da Mourinha (Campo Maior), a do Carro, ou Ponte dos Mouros, e a do Muro dos Mouros (Serpa), também se encontram toponimicamente conotadas com a presença islâmica e o maravilhoso que ela invoca (Quiniela, Cardoso e Mascarenhas, 1986, 66, 67, 86-91).

Nos últimos dias de Março de 1994, os signatários procederam ao reconhecimento arqueológico da região sudoeste de Lagoa, tendo em 
vista a elaboração do levantamento arqueológico concelhio, solicitado por aquela Camara Municipal. Verificámos, então, que na zona conhecida como Presa dos Mouros não se encontrava qualquer obra hidráulica antiga. Na verdade, a barragem que dera origem a tal topónimo situava-se na foz da ribeira do Lajeai ou do Vale da Lapa, a cerca de $1 \mathrm{Km}$ para sul. O topónimo mudou de posição e a barragem entrou no quase esquecimento da população, sendo apenas conhecida por um ou outro dos habitantes mais velhos daquela zona (fig.l).

\section{A localização}

Os restos da barragem romana, outrora conhecida cómo Presa dos Mouros, situam-se na pequena linha de água denominada ribeira do Lajeai ou do Vale da Lapa, conforme acima referimos, apenas a trinta metros da sua foz. Esta corre no sentido norte-sul, num vale encaixado, de vertentes abruptas, com pouco mais de $1 \mathrm{Km}$ de extensão (fig. 1).

A construção agora dada a conhecer localiza-se a cerca de $3 \mathrm{Kms}$ a sudeste de Ferragudo e a $1 \mathrm{Km}$, naquela mesma direccão, do v.g. Boa Nova, possuindo o local as coordenadas Gauss W 678152 (seg. a C.M.P., 603, Portimão, esc. 1:25.000, S.C.E., 1987). Pertence à freguesia de Ferragudo e ao concelho de Lagoa. O seu substrato é rochoso, sendo constituído por calcários do Miocènico marinho. ${ }^{3}$

\section{A barragem}

Trata-se de uma estrutura perpendicular à linha de água mencionada (fig. 2), de que se conserva apenas a metade poente, construída com blocos irregulares de calcário da zona, dispostos na horizontal, ligados por argamassa de cal e areia (fig. 3). Os elementos de maiores dimensões formam ambos os panos exteriores da construção, cujo interior foi preenchido com blocos menores e pedras miúdas.

A argamassa é muito rica em cal, o que lhe confere cor branca, tendo-se utilizado areia quartzosa de grão médio (entre $0.5 \mathrm{~mm} \mathrm{e} 1 \mathrm{~mm}$ ) por certo obtida na praia vizinha. Os elementos maiores apresentam-se rolados e observam-se, na matriz, alguns pisólitos ferruginosos.

A parte conservada possui o paramento de jusante rectilíneo, embora ligeiramente inclinado, enquanto que o oposto apresenta ligeira curvatura, com convexidade voltada para montante. Mede, actualmente, 
$5.15 \mathrm{~m}$ de comprimento, $2.10 \mathrm{~m}$ de altura máxima e $3.00 \mathrm{~m}$ de espessura média. O seu comprimento primitivo deveria atingir o dobro do actual, podendo a sua altura ter alcançado os seis a sete metros, conforme sugerem o que julgamos serem os testemunhos das marcas em que se teria fundado a estrutura, nas rochas de ambos os lados da ribeira.

$\mathrm{O}$ troço existente encontra-se totalmente assoreado a montante e a parte desaparecida deve-se, por certo, tanto à erosão fluvial como à marinha. Com efeito, no decurso de tempestades, a ondulação deve atingir o local.

A área da albufeira era de cerca de $5000 \mathrm{~m}^{2}$, para uma altura primitiva de $6 \mathrm{~m}$, a que corresponde um volume armazenado de, aproximadamente, $10.000 \mathrm{~m}^{3}$. A bacia hidrográfica é, também, muito pequena, com apenas cerca de $1.3 \mathrm{Km}^{2}$, embora semelhante às das barragens de Espiche $\left(1.4 \mathrm{Km}^{2}\right)$ e Fonte Coberta $\left(1.9 \mathrm{Km}^{2}\right)$ (Quíntela, Cardoso e Mascarenhas, 1988, 21). No Quadro 1 apresentam-se as características principais desta construção, comparadas com as das restantes barragens romanas do Algarve.

\section{Discussão e conclusões}

Os testemunhos da barragem romana que temos vindo a referir, a sétima conhecida no Algarve e a vigésima quarta a sul do Tejo, indicam que, apesar de terem pertencido a uma das mais pequenas estruturas daquele tipo até agora identificadas no nosso país, era das que atingiria maior altura. A barragem mais alta, por ora conhecida a sul do Tejo, é a de Ponte dos Mouros (Lagoa, Silves), no Vale do Olival, sobre a ribeira de Porches, medindo, ainda, o sector conservado $6.5 \mathrm{~m}$ de altura.

$\mathrm{O}$ traçado rectilíneo e o muro de secção rectangular constituído por núcleo de opus incertum, revestido por paramentos de fiadas de blocos, e sem contrafortes, integram-na na forma construtiva mais comum encontrada em Portugal.

O mau estado de conservação não permite a observação de órgãos anexos, como orifícios de descarga ou de tomada de água, detectados em construções congéneres.

A alimentação da albufeira era assegurada pela pequena bacia hidrográfica da ribeira assinalada, curso de água que estaria seco, como acontece actualmente, grande parte do ano. Daí a vantagem que adviria em assegurar, no decurso das épocas mais pluviosas, o máximo volume 
de água armazenada, o que seria conseguido com estruturas preferencialmente altas, dado os vales em tais terrenos carbonatados serem, normalmente, fundos e encaixados. Assim se explica a elevada altura da estrutura em estudo tal como a da Ponte dos Mouros.

Verificada a impossibilidade de terem existido terrenos agrícolas ou uma villa, tanto a jusante desta barragem, onde se encontra, de imediato, a praia, como na zona envolvente, ocupada por encostas íngremes e de solos pedregosos, a sua construção parece residir na associação a eventual complexo industrial de salga e conserva de peixe, hoje desaparecido dada a forte erosão marítima, que tem feito recuar, significativamente, a costa meridional do Algarve.

Também a barragem antes referida e conhecida por Ponte dos Mouros, a cerca de $1 \mathrm{Km}$ da praia de Armação de Péra, com área da bacia hidrográfica maior $\left(3.2 \mathrm{Km}^{2}\right)$ e condicionantes muito idênticas, ter-se-á destinado ao apoio de instalação fabril do mesmo tipo, talvez a mencionada por Estácio da Veiga $(1887,368)$, já desaparecida no início do presente século, conforme informa Mesquita de Figueiredo (1906, 117).

Já em anteriores trabalhos, considerou-se a hipótese das barragens romanas de Comenda (Setúbal) e de Vale Tesnado Cerro da Vila (Loulé) terem servido, além das estruturas termais existentes em ambas as villae, os complexos industriais de salga de peixe, detectados junto àquelas (Quiniela, Cardoso e Mascarenhas, 1985, 73; 1986, 53). Aliás, a necessidade de água potável junto de tais unidades industriais encontra-se bem expressa na estação romana de Tróia, onde, no centro da instalação fabril existe um grande poço, donde a água seria elevada e, depois, distribuída pelo complexo fabril (Quiniela, Mascarenhas e Cardoso, 1989a e neste volume).

Julgamos que fica, assim, demonstrada a existência de barragens integradas em complexos industriais de salga e conserva de peixe, no sul de Portugal, para além das funções ligadas à rega, e ao abastecimento de villae e dos seus balneários.

É possível que a prospecção do litoral algarvio, onde a actual precipitação anual média, inferior a $600 \mathrm{~mm}$ (fig. 4), não deverá ser muito diferente da que se observava nos primeiros séculos da nossa era, dificultando a existência de reservas de água subterrânea, cuja captação era, ainda, prejudicada pela natureza calcária dos terrenos, considerando os meios técnicos da época, conduza à identificação de novas pequenas barragens semelhantes à agora dada a conhecer, única forma que os Romanos dispunham de obter água para os diversos fins indicados. 
Quadro 1 - Características principais das barragens romanas do Algarve

\begin{tabular}{|c|c|c|c|c|}
\hline DESIGNAÇÃO & $\begin{array}{l}\text { TIPOLOGIA } \\
\text { (ESTRUTURA/ } \\
\text { /PLANTA }\end{array}$ & $\begin{array}{l}\text { DIMENSÕES } \\
(\mathrm{m})\end{array}$ & $\begin{array}{c}\text { ÁREA DA BACIA } \\
\text { HIDROGÁFICA } \\
\left(\mathrm{km}^{2}\right)\end{array}$ & $\begin{array}{l}\text { UTILIZAÇÃO } \\
\text { PROVÁVEL }\end{array}$ \\
\hline Álamo & $\mathrm{MC} / \mathrm{R}$ & $\begin{array}{l}\mathrm{H}=3,0 \mathrm{~L}=50 \\
\mathrm{e}=3,0 \text { (na base } \\
\text { contrafortes: } \\
\mathrm{e}=1,5 \\
\text { afast. }=2,3\end{array}$ & 0,3 & Abastecimento \\
\hline Santa Rita & $\mathrm{DMC} / \mathrm{R}$ & $\begin{array}{l}H=2,2 \mathrm{~L}=50 \\
\mathrm{e}=3,2 \\
\text { contrafortes: } \\
\mathrm{e}=1,0 \\
\text { afast. }=6,0\end{array}$ & 0,3 & Rega \\
\hline $\begin{array}{c}\text { Vale } \\
\text { Tesnado }\end{array}$ & $\mathrm{MR} / \mathrm{C}$ & $\begin{array}{l}H=1,2 \mathrm{~L}=220 \\
\mathrm{e}=0,7 \\
(2 \text { contrafortes })\end{array}$ & 37,5 & $\begin{array}{l}\text { Abastecimento } \\
\text { Indústria de } \\
\text { salga de peixe }\end{array}$ \\
\hline $\begin{array}{l}\text { Ponte dos } \\
\text { Mouros }\end{array}$ & $\mathrm{MC} / \mathrm{C}$ & $\begin{array}{l}H=6,5 \mathrm{~L}=32 \\
e=3,9 \\
\text { contrafortes }(1) \\
e=2,3\end{array}$ & 3,2 & $\begin{array}{l}\text { Indústria de } \\
\text { salga de peixe }\end{array}$ \\
\hline $\begin{array}{l}\text { Fonte } \\
\text { Coberta }\end{array}$ & $\mathrm{MR} / \mathrm{R}$ & $\begin{array}{l}H=2,6 L=75 \\
e=2,6\end{array}$ & 1,9 & $\begin{array}{c}\text { Abastecimento } \\
\text { e rega }\end{array}$ \\
\hline Espiche & $\mathrm{MR} / \mathrm{R}$ & $\begin{array}{l}\mathrm{H}=2,5 \mathrm{~L}=15 \\
\mathrm{e}=1,3\end{array}$ & 1,4 & - \\
\hline $\begin{array}{c}\text { Presa } \\
\text { dos Mouros }\end{array}$ & $\mathrm{MR} / \mathrm{R}$ & $\begin{array}{l}\mathrm{H}=2,1 \mathrm{~L}=5 \\
\mathrm{e}=3,0\end{array}$ & 1,3 & $\begin{array}{c}\text { Indústria de } \\
\text { salga de peixe }\end{array}$ \\
\hline
\end{tabular}

Convenções

\section{Estrutura}

MR - Muro de secção rectangular

MC - Muro com contrafortes a jusante

DMC - Duplo muro com aterro intermédio e contrafortes a jusante
Planta
Dimensões
$\mathrm{R}$ - Rectilínea
$\mathrm{H}$ - altura máxima visível
C - Curvilínea
$\mathrm{L}$ - desenvolvimento
e - espessura. 


\section{BIBLIOGRAFIA}

CARdoso, J.L., 1990, Barragens romanas do Algarve, Encontro de Arqueologia do Algarve, pp. 85-107, Delegação Regional do Sul da Secretaria de Estado da Cultura, Faro.

FARIA, J.C., e Ferreira, M.A., 1990, Aqueduto e barragem romanos do bairro Rio de Clérigos (Alcácer do Sal), Conimbriga, vol. XXIX, pp. 103-106, II ests.

FigueIREDO, A.M. de, 1906, Ruines d'antiques établissements à salaisons sur le littoral sud du Portugal, Bulletin Hispanique, tome VII, pp. 109-121.

Gomes, M.V., e Gomes, R.V., 1988, Levantamento Arqueológico Bibliográfico do Algarve, Delegação Regional do Sul da Secretaria de Estado da Cultura, 225 pp., Faro.

OliveirA, F.X. d'A., 1898, As Mouras Encantadas e os Encantamentos no Algarve, Typographya Burocrática, XXV +229 pp., 7 ests, Tavira.

QuíntelA, A. de C., Cardoso, J.L., e Mascarenhas, J.M., 1985, Barragens romanas do Sul de Portugal. Contribuição para o seu inventário e caracterização, Recursos Hídricos, voi 6, pp. 91-77.

1986, Aproveitamentos Hidráulicos Romanos a Sul do Tejo, Ministério do Plano e da Administração do Território, 236 pp., 74 figs, 128 ests, Lisboa.

1987, Roman dams in southern Portugal, Water Power \& Dams Construction, n. ${ }^{\circ}$ 70, pp. 38-40.

1988, Barragens romanas do Algarve, 5. Congresso do Algarve, voi. 1, pp. 19-27, Racal Clube, Silves.

1989, Barragens Antigas em Portugal, a sul do Tejo, Cuadernos de San Benito, n. ${ }^{\circ}$ 2, pp. 77-108.

1989a, Primeiro estudo sobre uma instalação romana de captação, elevação e armazenamento de água em Tróia (Portugal), Colóquio de História y Medio Fisico, Instituto de Estudos Almerienses, pp. 337-352, 6 figs, Almería.

VEIGA, S.P.M.E. da, 1887, Antiguidades Monumentaes do Algarve, vol. II, Imprensa Nacional, pp. 306-609, XXVIII + XII + IV ests, 1 mapa, Lisboa.

Conimbriga, 32-33 (1993-1994), 137-144 


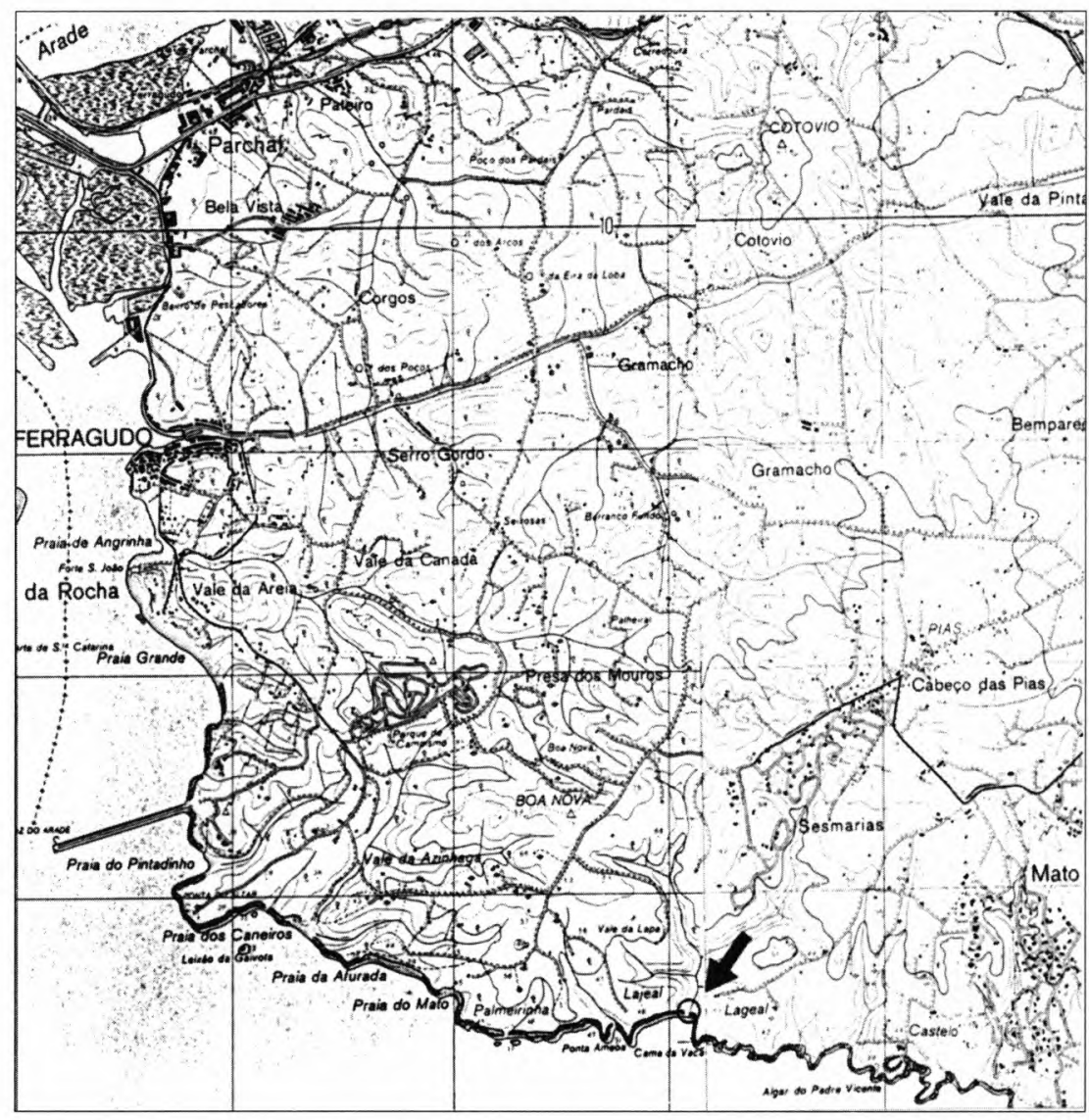

FIG. 1 - Localização da Presa dos Mouros (Lagoa) 


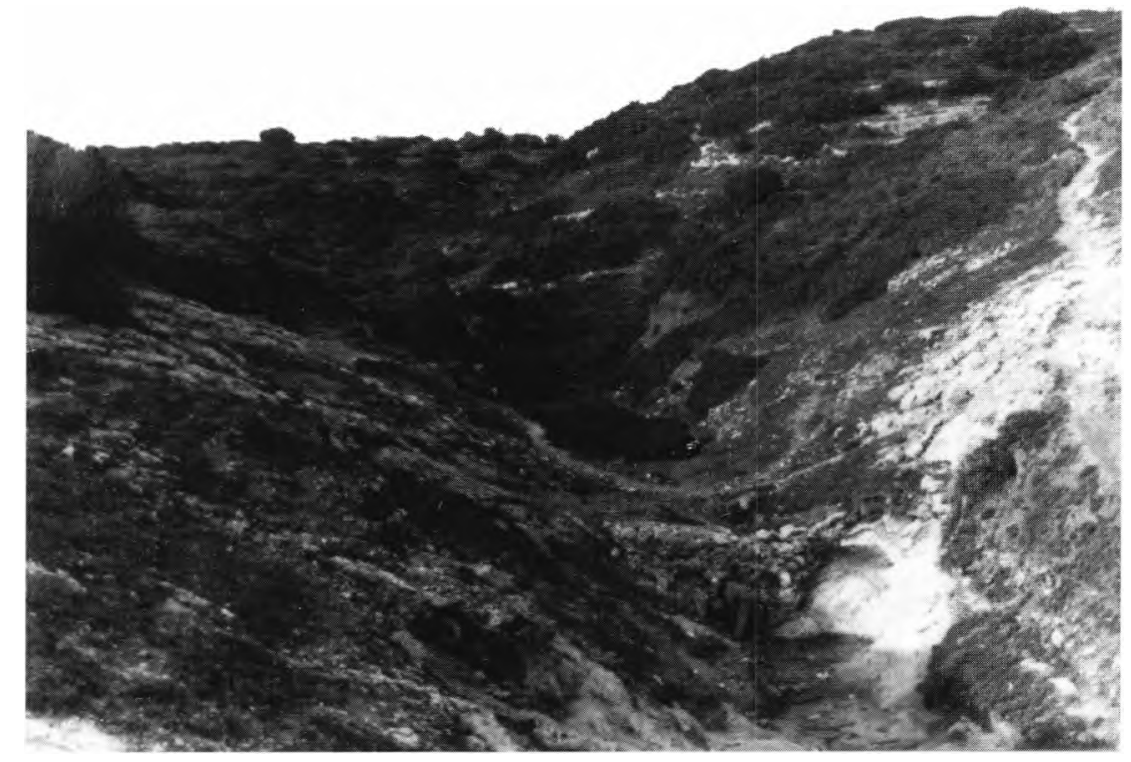

FIG. 2 - Presa dos Mouros. Vista de Sul (Foto M.V. Gomes, R IV/94-27)

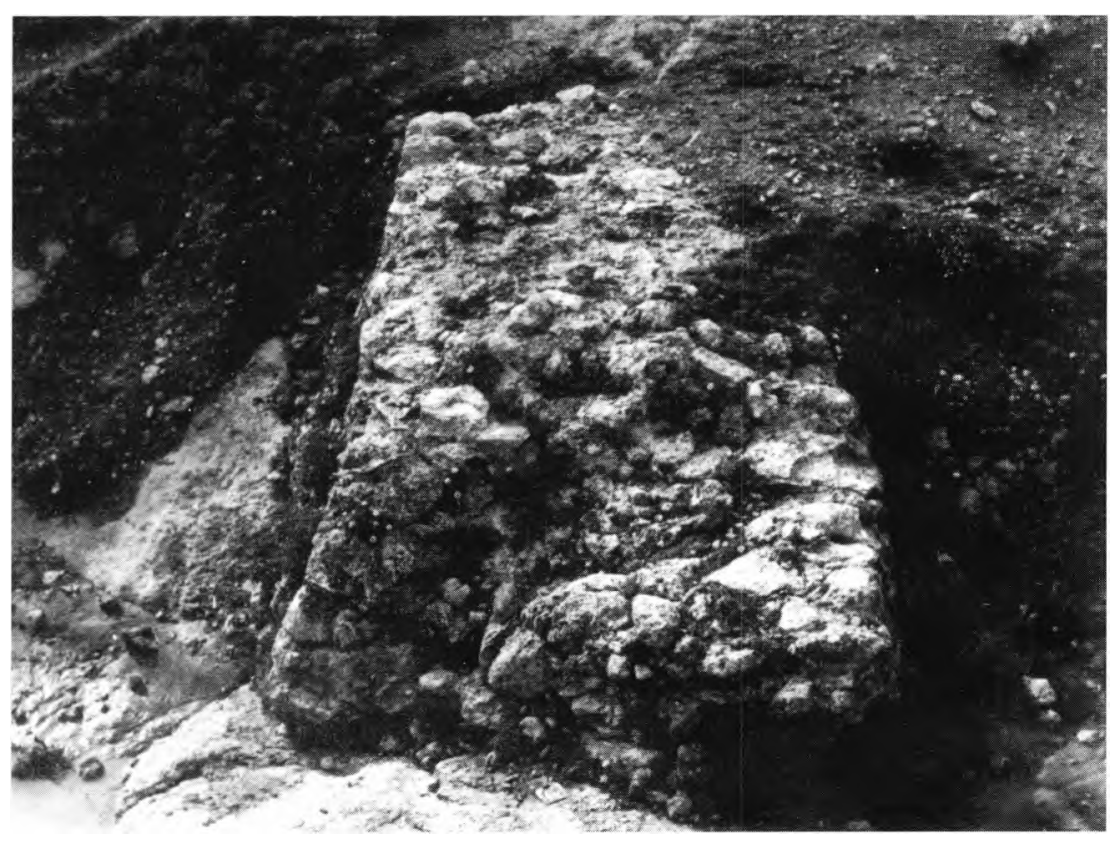

FIG. 3 - Presa de Mouros. Vista de nascente (Foto M.V. Gomes, R IV/94-14) 


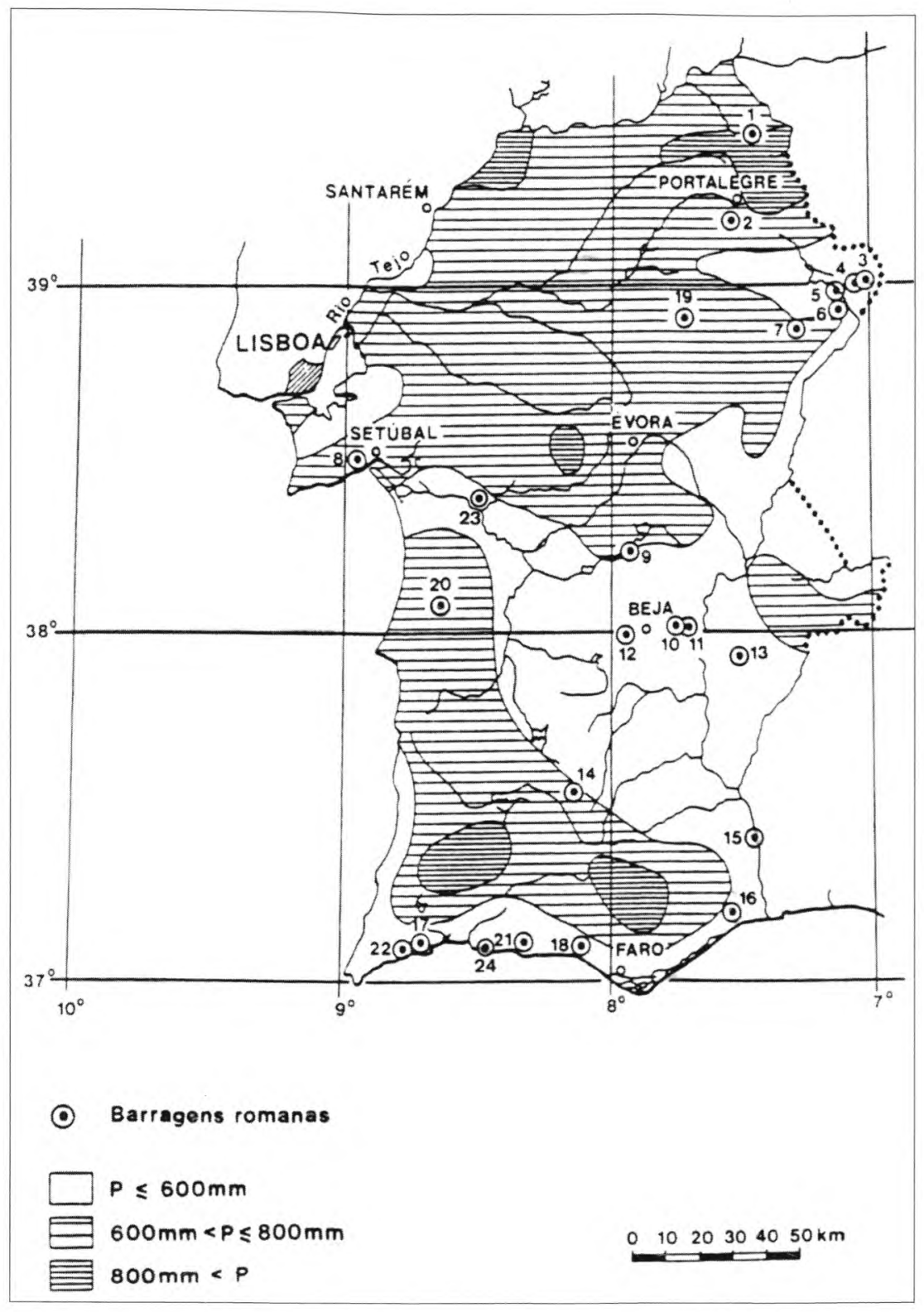

FIG. 4 - Barragens romanas e precipitação anual média, a sul do Tejo (seg. Quíntela, Cardoso e Mascarenhas, 1989, 80, fig. 1, completado). 1 - Tapada Grande; 2 - Almarjão; 3 - Muro; 4 - Olivã; 5 - Mourinha; 6 - Moralves; 7 - Carrão; 8 - Comenda; 9 - Nossa Senhora da Represa; 10 - Muro da Prega; 11 - Hortas de Baleizão; 12 - Pisões; 13 - Muro dos Mouros; 14 - Monte Novo do Castelinho; 15 - Álamo; 16 - Santa Rita; 17 - Fonte Coberta; 18 - Vale Tesnado; 19 - Carro (Ponte dos Mouros); 20 - Grândola; 21 - Ponte dos Mouros; 22 - Espiche; 23 - Rio de Clérigos; 24 - Presa dos Mouros 